\title{
Evaluation of Light Trap against Different Coloured Electric Bulbs for Trapping Phototrophic Insects
}

\author{
Akash Nirmal $^{1 *}$, Rupesh Kumar Gajbhiye ${ }^{1}$, Yogesh Kumar Sidar ${ }^{1}$ \\ and Jaya Laxmi Ganguli \\ Department of Entomology, College of Agriculture, Indira Gandhi Krishi Vishwavidyalaya, \\ Raipur, Chhattisgarh, India \\ *Corresponding author
}

\section{A B S T R A C T}

\begin{tabular}{l} 
Key w or d s \\
Evaluation, Red, \\
Blue, Green, \\
Yellow, Light trap. \\
\hline Article Info \\
\hline $\begin{array}{l}\text { Accepted: } \\
\text { 23 May } 2017 \\
\text { Available Online: } \\
\text { 10 June } 2017\end{array}$ \\
\hline
\end{tabular}

\section{Introduction}

Phototrophic insects are those which get attracted towards a light source. Seven colors in the light spectrum viz., violet, indigo, blue, green, yellow, orange and red fall under visible lights. Each color has a different wavelength and frequency. Red has the longest wavelength and the lowest frequency while violet has the shortest wavelength and the highest frequency. The wavelengths of visible lights range from 400-700 nanometers. As far as temperature is concerned red light is the coolest and blue is the warmest.

White light is the combination of all visible colours. It appears white because none of the light is absorbed and all is reflected back to the human eye. Black light consists of long wavelengths of ultraviolet light and is visible to insects, but not to humans. Light becomes visible to insects around the yellow part of the spectrum and ends at ultraviolet light (Ashfaq et al., 2005).

Light-trapping is a general term which covers all methods of attracting and/or capturing nocturnal insects with lamps that usually have a strong emission in the ultraviolet range of the spectrum, e.g. mercury vapour lamps, black light lamps or fluorescent tubes. Nocturnal Lepidoptera (moths), Trichoptera and Ephemeroptera are the insect groups which can be collected most efficiently by light-trapping but many nocturnal species in several other orders are rarely recorded with other methods, e.g. some Coleoptera (Steiner et al., 2009). 


\section{Materials and Methods}

\section{Geographical location and site}

Raipur is situated in mid-eastern part of Chhattisgarh at $21^{\circ} 14^{\prime}$, north latitude and $81^{\circ}$ 38 , east longitude with attitude of 298.15 meter above the mean sea level. The experiment was conducted at the experimental research farm, Department of Forestry, Indira Gandhi Krishi Vishwavidyalaya, Raipur during $45^{\text {th }}$ to $13^{\text {th }}$ standard week of 2014-15.

The experiment site, Raipur comes under the seventh agro-climatic region of India i.e. eastern plateau and hills which is termed as sub humid with hot summer and cold winter. The source of rainfall is south western monsoon. It receives an average annual rainfall of $1200-1400 \mathrm{~mm}$, mostly (85\%) concentrate during the period of June to September. A few showers expected during winters and occasionally during summer months. May is the hottest and December is the coolest month of the year. The weekly maximum temperature rise up to $46^{\circ} \mathrm{C}$ during summer and minimum temperature reaches as low as to $6^{\circ} \mathrm{C}$ during winter season.

\section{Experiment detail}

The experiment was conducted by using simple incandescent light trap model with five coloured tungsten filament 60 watt bulb viz. blue, yellow, red, green and ordinary (without colour). All five light traps were installed at 3 meter above ground level and 1 meter apart from each other to let the insect to orient toward their most favorite colour. Light traps were operated from 7 p.m. to 10:30 p.m. daily and order wise separation and number of insects caught were recorded. Order wise separation is based on insects a character which is described in various books of entomology i.e. Moths and Butterfly belongs to order-Lepidoptera.

\section{Results and Discussion}

Table 01 represents the percentage of the total number of insects caught in various coloured light traps. According to the percentage of insects collected, the lowest number of insects were attracted towards red colour light i.e. 10.36 per cent. This finding is in accordance with Ashfaq et al., (2005) and Pate and Curtis (2001) who also found that the lowest numbers of insects were trapped in red colored light among the various coloured lights tested. Ordinary light attracted the highest number of 41.54 per cent insects followed by yellow light 21.83 per cent, while blue and green light attracted 13.73 and 12.52 per cent insects respectively.

Percentage of insects attracted towards different coloured light was computed separately and tabulated in table 02. Blue colour light attracted maximum of Hemiptera 44.66 per cent followed by Lepidoptera (26.76\%), Diptera (25.15\%) and Ephemeroptera (3.43\%) (Fig.01). Yellow colour light also trapped maximum percent of Hemiptera $(54.49 \%)$ followed by Diptera (24.00\%), Lepidoptera (19.22\%) and Ephemeroptera (2.27\%) (Fig.02). Similarly Red colour light also attracted maximum Hemiptera 56.59 per cent followed by Diptera $(24.46 \%)$, Lepidoptera $(15.82 \%)$ and Ephemeroptera (3.11\%) (fig.03) and so also green colour light attracted maximum Hemiptera 59.72 per cent followed by Diptera (20.49\%), Lepidoptera (14.68\%) and Ephemeroptera (5.15\%) (Fig.04). The same trend was observed in ordinary light which also attracted maximum Hemiptera 40.31 per cent followed by Lepidoptera (25.71\%), Diptera (23.80\%), Ephemeroptera (4.60\%), Coleoptera $(3.11 \%)$ and Orthoptera $(2.45 \%)$ insects (Fig.05). Thus Hemipterans dominated the catches in all the different coloured traps and Coleopterans and Orthopterans were attracted only towards ordinary tungsten filament light. 

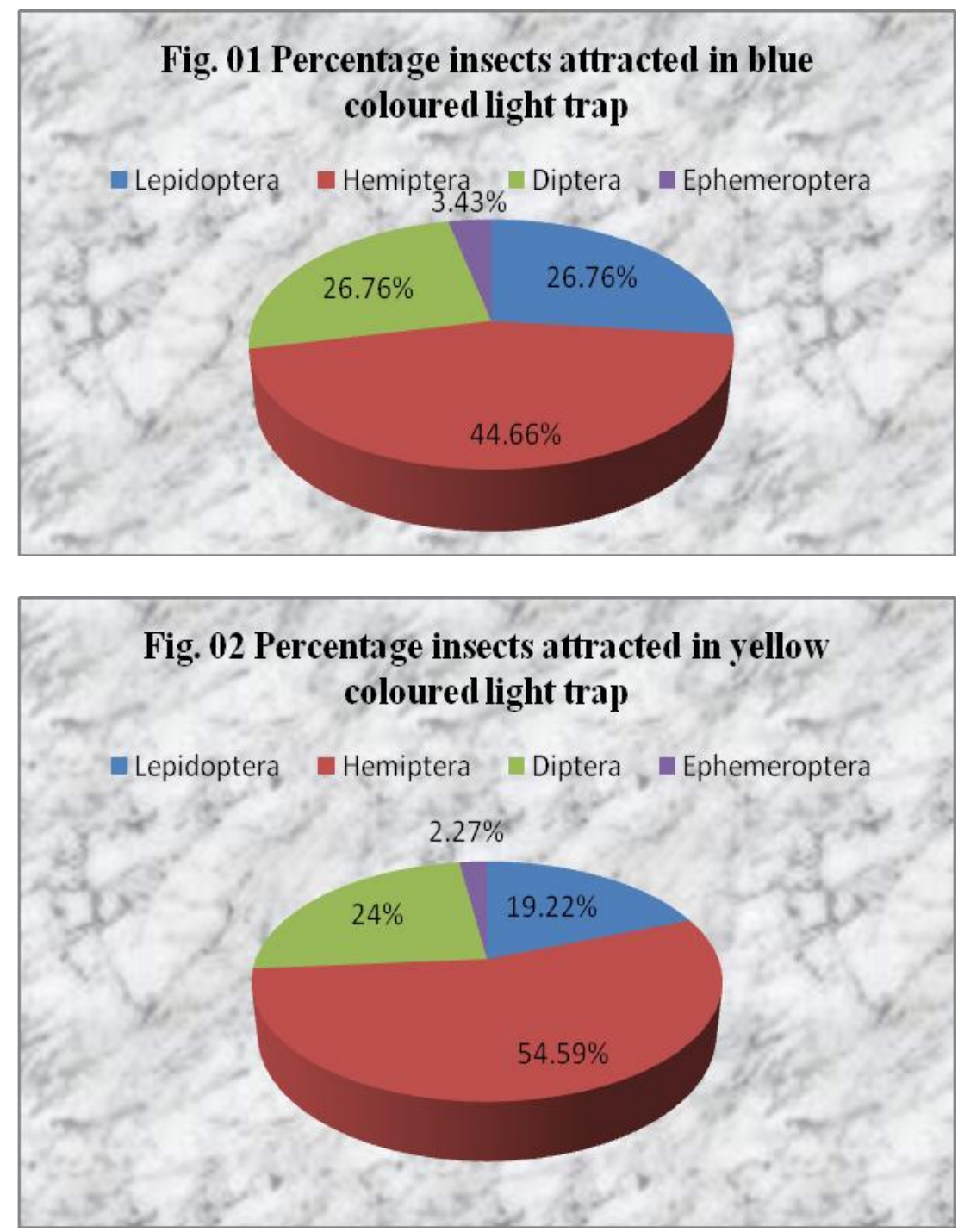

Fig. 03 Percentage insects attracted in red coloured light trap

- Lepidoptera Hemiptera ${ }_{3.11 \%}$ Diptera , Ephemeroptera

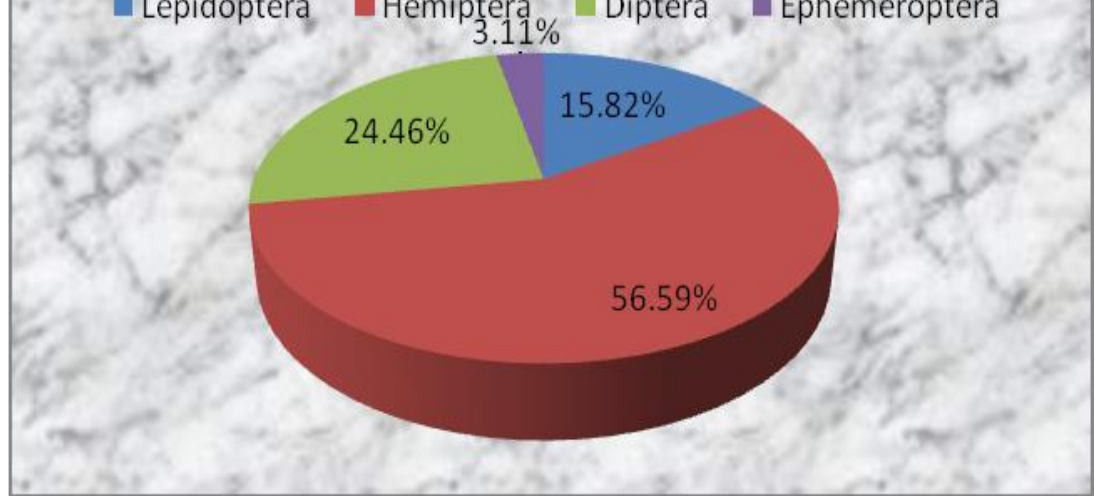



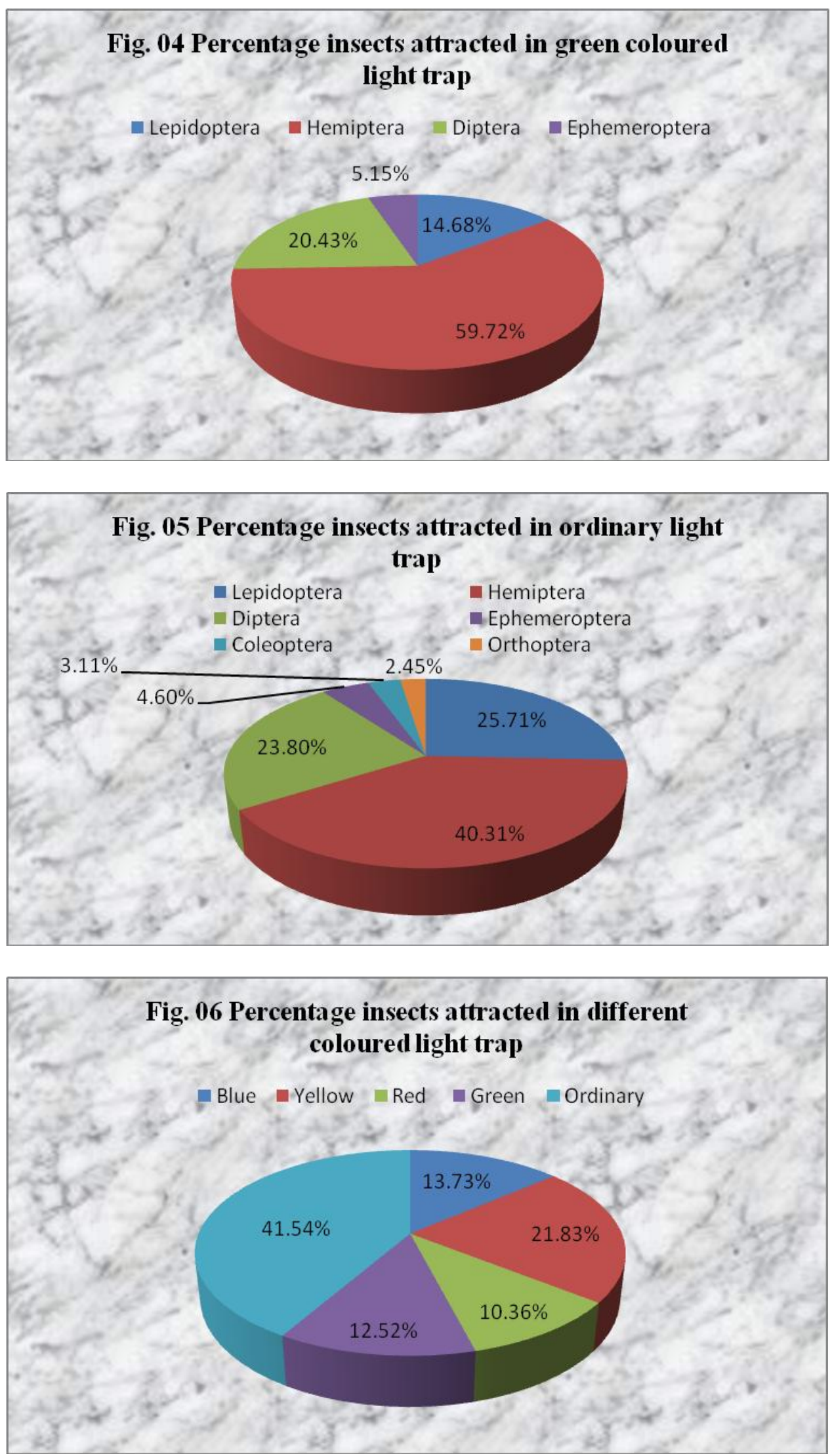
Table.1 Percentage of insects attracted in different coloured light trap

\begin{tabular}{|l|c|c|}
\hline S. No. & Colour of light & Insect population (\%) \\
\hline 01. & Ordinary & 41.54 \\
\hline 02. & Yellow & 21.83 \\
\hline 03. & Blue & 13.73 \\
\hline 04. & Green & 12.52 \\
\hline 05. & Red & 10.36 \\
\hline
\end{tabular}

Table. 2 Proportion of insects attracted in different coloured lights (\%)

\begin{tabular}{|l|l|l|l|l|l|l|l|}
\hline S.N. & Insect orders & Blue & Yellow & Red & Green & Ordinary & Mean \\
\hline 01. & Hemiptera & 44.66 & 54.49 & 56.59 & 59.72 & 40.31 & 51.15 \\
\hline 02. & Diptera & 26.76 & 24.00 & 24.46 & 20.49 & 25.71 & 24.28 \\
\hline 03. & Lepidoptera & 25.15 & 19.22 & 15.82 & 14.68 & 23.80 & 19.73 \\
\hline 04. & Ephemeroptera & 3.43 & 2.27 & 3.11 & 5.15 & 4.60 & 3.71 \\
\hline 05. & Coleoptera & - & - & - & - & 3.11 & 3.11 \\
\hline 06. & Orthoptera & - & - & - & - & 2.45 & 2.45 \\
\hline
\end{tabular}

These findings are partially not in agreement with the findings of Sharma et al., (2013) and Dadmal and Khaddekar (2014) who mentioned that Lepidoptera and Coleoptera were the dominant orders respectively in the light trap catches, however hemiptera was the second largest order in the findings of both the authors. Considering the mean trap catches among the tested five colour lights, hemipterans were more attracted to green red and yellow; dipterans towards blue; ordinary and red lights; lepidoptrans only to blue and ordinary lights; ephemerropterans to green and ordinary lights.

Thus, the present study provides scientific information on insect attraction towards different light spectrums and their order wise distribution with respect to different coloured light under Agro-forestry field condition. Study concludes that ordinary tungsten filament light attracted more orders of insects while blue, yellow, red and green trapped only four orders of insects namely Hemiptera, Diptera, Lepidoptera and Ephemeroptera.

\section{Acknowledgements}

Authors are gratefull Dr Jaya Laxmi Ganguli Asst. Professor, Department of Entomology College of Agriculture, I.G.K.V. for his full support, constant enthusiasm and motivation. A special thanks to Dr. Rajeev Gupta, H.O.D., and Department of Entomology for his guidance during the present study.

\section{References}

Ashfaq, M., Khan Rashid, A., Khan, M.A., Rasheed, F., Hafeez, S. 2005. Insect orientation to various colour light in the Agricultural biomass of Faisalabad. Pak. Entomol., 27(1): 49-52.

Dadmal, S.M., Khadakkar, S. 2014. Insect founal diversity collected through light Trap at Akola vicinity of Maharashtra with reference to Scarabaeidae of Coleoptera. J. Entomol. Zool., 2(3): 4448. 
Pate, J., Curtis, A. 2001. Insects response to different wavelengths of light in New River State Park, Ash County, North Carolina. Field Biol. Ecol., 12(2): 4-8.

Sharma, A.K., Bisen, U.K. 2013. Taxonomic documentation of insect pests fauna of vegetable ecosystem collected in light trap. Int. J. Environ. Sci. Develop. Monitoring, 4(3): 4-11.

Steiner, A., Hauser, C.L. 2009. Chapte-16, Recording insects by light trap. Berlin, 401-406.

\section{How to cite this article:}

Akash Nirmal, Rupesh Kumar Gajbhiye, Yogesh Kumar Sidar and Jaya Laxmi Ganguli. 2017. Evaluation of Light Trap against Different Coloured Electric Bulbs for Trapping Phototrophic Insects. Int.J.Curr.Microbiol.App.Sci. 6(6): 2068-2073.

doi: https://doi.org/10.20546/ijcmas.2017.606.245 